\title{
PPAR $\gamma$ activation reduces ischemia/reperfusion-induced metastasis in a murine model of hepatocellular carcinoma
}

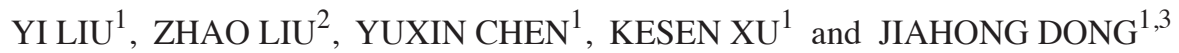 \\ ${ }^{1}$ Department of Hepatobiliary Surgery, Qilu Hospital, Shandong University, Jinan, Shandong 250012; \\ ${ }^{2}$ Department of Hepatobiliary Surgery, Jinan Central Hospital, Shandong University, Jinan, Shandong 250013; \\ ${ }^{3}$ Department of Hepatobiliary Surgery, Chinese PLA General Hospital, Beijing 100853, P.R. China
}

Received July 21, 2014; Accepted August 19, 2015

DOI: 10.3892/etm.2015.2934

\begin{abstract}
Ischemia/reperfusion (I/R) injury during liver resection or transplantation for the treatment of hepatocellular carcinoma (HCC) may increase the risk of metastasis. Peroxisome proliferator-activated receptor- $\gamma$ (PPAR $\gamma$ ) activation has been observed to exert a protective effect against hepatic I/R injury. However, whether PPAR $\gamma$ activation exerts a protective effect against I/R-associated liver metastasis remains unknown. Therefore, the present study aimed to investigate the effects of the PPAR agonist rosiglitazone and the specific PPAR $\gamma$ antagonist GW9662 on tumor metastasis following hepatic I/R. An experimental mouse model of hepatic I/R-induced HCC metastasis was designed in order to determine the effects of I/R on tumor metastasis in the liver. Four groups were established: Sham, control (I/R), rosiglitazone (Ro) and rosiglitazone with GW9662 (Ro + GW) groups. In the latter two groups, the treatments were administered intravenously $1 \mathrm{~h}$ prior to the induction of ischemia. Tumor load was measured 12 days after the procedure. Furthermore, tissue analyses were conducted to determine the expression levels of alanine aminotransferase, myeloperoxidase (MPO), matrix metalloproteinase (MMP)-9, vascular cell adhesion molecule (VCAM)-1, nuclear factor (NF)- $\kappa$ B and PPAR $\gamma$. Rosiglitazone pretreatment appeared to significantly mitigate hepatic I/R injury, as indicated by serological and histological analysis. The levels of VCAM-1, MPO and MMP-9 expression in the Ro group were significantly reduced at $8 \mathrm{~h}$ following ischemia compared with those in the control and Ro + GW groups. In addition, rosiglitazone inhibited the I/R-induced activation of NF- $\kappa$ B, and GW9662 attenuated the inhibitory effect. To the best of our knowledge, the present study is the first to report on the expression and the functional roles of PPAR $\gamma$
\end{abstract}

Correspondence to: Dr Jiahong Dong, Department of Hepatobiliary Surgery, Qilu Hospital, Shandong University, 107 Wenhua West Road, Jinan, Shandong 250012, P.R. China

E-mail: dong_jiahong@126.com

Key words: hepatic metastasis, peroxisome proliferator-activated receptor- $\gamma$, ischemia/reperfusion, rosiglitazone in I/R-associated metastasis. Short-term treatment of mice with rosiglitazone, a potent PPAR $\gamma$ agonist, confers protective effects against hepatic I/R-associated metastasis. Thus, PPAR $\gamma$ may be a potential therapeutic target for the protection of the liver against I/R-associated metastasis.

\section{Introduction}

Hepatocellular carcinoma (HCC) is one of the most common types of malignant tumor among Chinese individuals, and typically exhibits an extremely poor prognosis (1). Surgical removal is currently the preferred option for the treatment of HCC in the majority of cases (2). However, only 40-50\% of patients that undergo surgery survive for $\geq 5$ years, and the majority ultimately succumb to HCC recurrence in the liver $(2,3)$. Although the high rate of tumor recurrence may be a result of residual tumor cells, there may be an association between the conduct of the surgery and recurrence in the liver, as previous studies have indicated that surgical stress itself increases the chances of tumor metastasis (4-6). Thus, to reduce the recurrence of HCC following an hepatectomy or liver transplantation, the cause underlying the emergence of metastasis following surgery requires investigation.

In cases of HCC, hematogenous metastasis is the primary cause of metastasis, during which a number of complex interactions occur between tumor cells and the host $(7,8)$. In the classical process of hematogenous cancer metastasis, the critical steps of extravasation include tumor cell adhesion onto the vascular endothelium (docking), transition to more established cell contacts (locking), migration through the vascular wall (foothold) and subsequent remodeling of the target tissue (colonization) (9,10). Various mediators, including chemokines, adhesion molecules, kinases and matrix metalloproteinases (MMPs) are implicated in tumor transendothelial migration (TEM). Therefore, identifying any alterations in the expression of these molecules following hepatic ischemia/reperfusion (I/R) may aid in defining future targets for tumor therapeutics.

Major blood loss during liver resection and the requirement for perioperative blood transfusion negatively affects perioperative morbidity, mortality and long-term outcomes $(11,12)$. Therefore, strategies to control intraoperative bleeding are presently applied worldwide. However, such measures may lead to $\mathrm{I} / \mathrm{R}$ injury of the liver parenchyma, which is a major cause of 
hepatic failure following surgery. I/R damage following standard clamping is characterized by widespread liver cell death and microcirculatory disturbances. This damage is mediated by processes including the induction of free-radical formation, upregulation of inflammatory cytokines and infiltration of polymorphonuclear neutrophils (PMNs) into the hepatic parenchyma $(13,14)$, all of which may produce an ideal milieu for tumor cell TEM $(15,16)$. Approaches designed to limit I/R damage, which involve controlling cytokine storms following I/R injury, may be capable of reducing the incidence of metastasis following surgery.

Peroxisome proliferator-activated receptor- $\gamma(\operatorname{PPAR} \gamma)$ is one of the three subtypes of the nuclear receptor PPARs $(17,18)$. Ligands of PPAR $\gamma$, such as rosiglitazone, exert the beneficial effect of reducing serum glucose levels in diabetic patients. However, these ligands can also induce the negative transcriptional regulation of the nuclear factor $(\mathrm{NF})-\kappa \mathrm{B}$ signaling pathway, which increases the expression of adhesion molecules and the production of chemokines, and which upon reperfusion recruit neutrophils to the site of injury $(18,19)$. Therefore, we hypothesized that $\mathrm{I} / \mathrm{R}$ injury accelerates the metastasis of pre-existing tumor cells in the circulation. Thus, the aim of the present study was to investigate the effects of the PPAR $\gamma$ agonist, rosiglitazone, on I/R-associated metastasis in mice. In addition, the influence of GW9662, a specific PPAR $\gamma$ antagonist, was investigated.

\section{Materials and methods}

Reagents. Rosiglitazone and GW9662 were purchased from Cayman Chemical Company, Inc. (Ann Arbor, MI, USA). Polyclonal rabbit anti-mouse VCAM-1 antibody (sc8304) was acquired from Santa Cruz Biotechnology, Inc. (Dallas, TX, USA) and NF- $\kappa B$ and PPAR $\gamma$ antibodies (\#3034 and \#2443, respectively) were from Cell Signaling Technology, Inc. (Danvers, MA, USA). All other reagents were purchased from ZSJQ Biotechnology (Beijing, China) unless otherwise stated.

Experimental animals. All experiments were conducted in accordance with the guidelines of the animal welfare committee of the Shandong University Medical Center (Jenan, China). A total of 64 male BALB/c mice, aged 6-7 weeks, were purchased from the Academy of Military Medical Sciences of PLA (Beijing, China). All animals were housed under standard laboratory conditions and allowed free access to water and food. All animal experiments were conducted in accordance with the principles and procedures outlined in the Administration Regulations on Laboratory Animals of Beijing Municipality. The protocols for animal experiments were approved by the Animal Experimentation Committee of the Academy of Military Medical Sciences of the PLA (Beijing, China).

Cell culture. $\mathrm{H} 22$ is a mouse HCC cell line with a high potency for liver metastases, and was purchased from the Cell Culture Center of the Chinese Academy of Medical Sciences (Beijing, China). The $\mathrm{H} 22$ cells were isolated from the ascites of BALB/c mice on day 7 following an abdominal injection of $\mathrm{H} 22$ cells $\left(0.2 \mathrm{ml}, 1 \times 10^{8}\right.$ cells $\left./ \mathrm{ml}\right)$. The cell culture medium consisted of RPMI-1640 supplemented with $10 \%$ fetal bovine serum and
$100 \mathrm{U} / \mathrm{ml}$ streptomycin and penicillin solution, all of which were provided by the Research Institute of Hepatobiliary Surgery, Chinese PLA General Hospital (Beijing, China). Cells were incubated at $37^{\circ} \mathrm{C}$ in humidified air with $5 \%$ $\mathrm{CO}_{2}$ and $95 \% \mathrm{O}_{2}$. For usage, tumor cells were suspended in phosphate-buffered saline at a density of $1 \times 10^{7}$ cells $/ \mathrm{ml}$. Each mouse received an intravenous injection of $5 \times 10^{5}$ cells suspended in $50 \mu 1$ solution.

Mouse model of tumor metastasis following hepatic I/R. Standardized surgical procedures were performed as described by van der Bilt et al (20) with appropriate adjustments. Briefly, the mice were anesthetized with pentobarbital sodium (60 mg/kg, intraperitoneally). A midline laparotomy was performed and an atraumatic clip was used to interrupt blood supply to the left lateral and median lobes of the liver (corresponding to $\sim 70 \%$ of the liver mass). After $45 \mathrm{~min}$ of partial hepatic ischemia and 45 min reperfusion, $\mathrm{H} 22$ cells $(50 \mu \mathrm{l})$ were injected into the portal vein via a 29-gauge needle attached to a 1-ml syringe. To prevent bleeding and peritoneal dissemination of the tumor cells, a sterile cotton sponge was applied to the injection site for 1-3 min until bleeding stopped. The abdominal wound was then closed in two layers.

Drugs and treatments. The mice were allocated at random into four groups: Sham, for which the vessels to the left lateral and median lobes of the liver were dissected but not interrupted; control, administered $10 \%$ dimethyl sulfoxide (DMSO; $2 \mathrm{ml} / \mathrm{kg}$ ) $1 \mathrm{~h}$ prior to ischemia; Ro, administered rosiglitazone $(1 \mathrm{mg} / \mathrm{kg}) 1 \mathrm{~h}$ prior to ischemia; and Ro $+\mathrm{GW}$, administered rosiglitazone $(1 \mathrm{mg} / \mathrm{kg})$ and GW9662 $(1 \mathrm{mg} / \mathrm{kg}) 1 \mathrm{~h}$ prior to ischemia. Rosiglitazone and GW9662 were prepared in $10 \%$ DMSO and injected intravenously $1 \mathrm{~h}$ prior to ischemia, respectively. For all experiments, the drug concentrations were calculated such that all animals received equal volumes of DMSO.

All experimental groups are outlined in Table I. In order to establish the effect of I/R on hepatic metastasis, mice from the sham and control groups ( $n=10$ per group) were sacrificed by cervical dislocation 12 days after surgery. Metastasis of the ischemic and non-ischemic lobes was scored as the hepatic replacement area (HRA) (20). HRA was defined as the percentage of liver tissue replaced by tumor tissue, based on four non-sequential hematoxylin and eosin (H\&E)-stained sections. The images were analyzed using a Leica microscope camera and Biosens Digital Imaging System analysis system, version 1.6 (Leica Microsystems, Beijing, China). Survival time was recorded until 12 days after the surgery.

The second experiment was designed to determine the effect of the drugs on hepatic metastasis in mice. Mice from the Ro and Ro + GW groups ( $=10$ per group) were sacrificed 12 days after surgery. Liver samples were obtained and the metastasis and survival time were scored as described above.

The third experiment was designed to quantify the expression of various metastasis-associated proteins. Mice were sacrificed at 2, 8 and $24 \mathrm{~h}$ after the initiation of reperfusion ( $n=6$ per group at each time-point). Liver samples were obtained for evaluation by light microscopy or storage at $-80^{\circ} \mathrm{C}$ until tissue analysis. 
Table I. Description of experimental groups.

\begin{tabular}{|c|c|c|c|c|}
\hline Experiment & Rationale & Group & Procedure & $\mathrm{n}$ \\
\hline \multirow[t]{2}{*}{1} & $\begin{array}{l}\text { Establish the effect of } \mathrm{I} / \mathrm{R} \text { on } \\
\text { hepatic metastasis }\end{array}$ & Sham & $\begin{array}{l}\text { Laparotomy, liver manipulation, intraportal } \\
\text { injection of H22 tumor cells and closure. } \\
\text { Sacrificed } 12 \text { days after surgery }\end{array}$ & 10 \\
\hline & & Control & $\begin{array}{l}\text { Intraportal injection of } \mathrm{H} 22 \text { tumor cells } \\
\text { after partial hepatic ischemia. Sacrificed } \\
12 \text { days after surgery }\end{array}$ & 10 \\
\hline \multirow[t]{2}{*}{2} & $\begin{array}{l}\text { Determine the effect of drugs } \\
\text { on hepatic metastasis }\end{array}$ & Ro & $\begin{array}{l}\text { As in the control group, but treated with } \\
\text { rosiglitazone } 1 \mathrm{~h} \text { prior to ischemia }\end{array}$ & 10 \\
\hline & & $\mathrm{Ro}+\mathrm{GW}$ & $\begin{array}{l}\text { As in the control group, but treated with } \\
\text { rosiglitazone }+ \text { GW9662 } 1 \mathrm{~h} \text { prior to ischemia }\end{array}$ & 10 \\
\hline \multirow[t]{4}{*}{3} & $\begin{array}{l}\text { Quantify the expression of } \\
\text { metastasis-associated proteins }\end{array}$ & Sham & $\begin{array}{l}\text { Samples collected after } 45 \text { min sham ischemia } \\
\text { and } 2,8 \text { and } 24 \text { h reperfusion }\end{array}$ & $6^{\mathrm{a}}$ \\
\hline & & Ro & $\begin{array}{l}\text { Treated with rosiglitazone } 1 \mathrm{~h} \text { prior to } \\
\text { ischemia. Samples collected after } 45 \mathrm{~min} \\
\text { ischemia and } 2,8 \text { and } 24 \mathrm{~h} \text { reperfusion }\end{array}$ & $6^{\mathrm{a}}$ \\
\hline & & Control & $\begin{array}{l}\text { Samples collected after } 45 \mathrm{~min} \text { ischemia } \\
\text { and } 2,8 \text { and } 24 \text { h reperfusion }\end{array}$ & $6^{\mathrm{a}}$ \\
\hline & & $\mathrm{Ro}+\mathrm{GW}$ & $\begin{array}{l}\text { Treated with rosiglitazone }+ \text { GW9662 } 1 \mathrm{~h} \text { prior } \\
\text { to ischemia. Samples collected after } 45 \mathrm{~min} \\
\text { ischemia and } 2,8 \text { and } 24 \mathrm{~h} \text { reperfusion }\end{array}$ & $6^{\mathrm{a}}$ \\
\hline
\end{tabular}

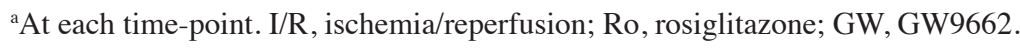

Histochemistry and immunohistochemistry. For light microscopy, sections of the left lobe of the liver were fixed in $10 \%$ phosphate-buffered formalin for $\geq 5$ days. The resulting paraffin-embedded sections $(5 \mu \mathrm{m})$ were stained with $\mathrm{H} \& \mathrm{E}$ for routine histological examination according to standard procedures. Vascular cell adhesion molecule (VCAM)-1 protein was stained using immunohistochemical techniques (streptavidin peroxidase). In brief, deparaffinized sections were incubated with $3 \% \mathrm{H}_{2} \mathrm{O}_{2}$ to block endogenous peroxidases and with $0.5 \%$ goat normal serum to block nonspecific binding sites. Polyclonal mouse anti-VCAM-1 antibodies (1:50) were used as primary antibodies. Biotinylated anti-goat rabbit immunoglobulin antibodies were used as secondary antibodies for streptavidin-biotin complex peroxidase staining. The labeling was visualized by immersing the slides in prepared diaminobenzidine solution (1:20) for 3-7 min. The slides were then examined using a light microscope (CKX31; Olympus, Shanghai Fulai Optical Technology Co., Ltd., Shanghai, China) and the VCAM-1 positive cells were counted in 10 high-power fields. The labeling index was expressed as the percentage of total hepatocytes counted.

Biochemical determinations. Alanine aminotransferase (ALT) and myeloperoxidase (MPO) levels were measured using ALT/GPT and MPO ELISA kits (ZSJQ Biotechnology, Inc., Beijing, China), following the manufacturer's protocol. Briefly, $100 \mathrm{mg}$ liver tissue was homogenized in $2 \mathrm{ml}$ buffer $\mathrm{A}$, which consisted of $3.4 \mathrm{mmol} / 1 \mathrm{KH}_{2} \mathrm{HPO}_{4}$ and $16 \mathrm{mmol} / 1 \mathrm{Na}_{2} \mathrm{HPO}_{4}$ at $\mathrm{pH}$ 7.4. After centrifugation for $20 \mathrm{~min}$ at $10,000 \mathrm{x} \mathrm{g}$, the pellet was resuspended in 10 volumes of buffer $\mathrm{B}$, which consisted of $43.2 \mathrm{mmol} / 1 \mathrm{KH}_{2} \mathrm{HPO}_{4}, 6.5 \mathrm{mmol} / 1 \mathrm{Na}_{2} \mathrm{HPO}_{4}$,
$10 \mathrm{mmol} / 1$ ethylenediaminetetraacetic acid and $0.5 \%$ hexadecyltrimethylammonium at $\mathrm{pH}$ 6.0. Liver samples were subsequently sonicated for $10 \mathrm{sec}$ following treatment with 3,3',5,5'-tetramethylbenzidine and the optical density was recorded at $655 \mathrm{~nm}$ using a UV-2000 spectrophotometer (UNICO, Dayton, NJ, USA).

Electrophoretic mobility shift assay (EMSA). Nuclear extracts from the ischemic lobe of the mouse liver tissue were prepared according to previously described methods (17) and analyzed using an EMSA. The 5'-biotin-labeled probes for PPAR $\gamma$ and NF- $\kappa$ B BiotinLight ${ }^{\mathrm{TM}}$ Chemiluminescent EMSA kit (Exprogen Biotechnology, Inc., Beijing, China) were purified with QIAquick Gel Extraction kit (Qiagen, Hilden, Germany). An EMSA was performed using a BiotinLight ${ }^{\mathrm{TM}}$ Chemiluminescent EMSA kit (Exprogen Inc., Beijing, China). A total of $2 \mathrm{mg}$ purified protein was incubated with the probe at $30^{\circ} \mathrm{C}$ for $20 \mathrm{~min}$ in a $20-\mathrm{ml}$ binding reaction containing $1 \mathrm{X}$ binding buffer, $5 \mathrm{mM} \mathrm{MgCl}, 2.5 \%$ glycerol, $0.05 \% \mathrm{NP}-40$, $1 \mathrm{mg}$ poly (dI-dC), and $10 \mathrm{fmol}$ biotin-labeled probe. Competitor experiments with 50- and 100-fold excesses of unlabeled probe as a specific competitor or poly (dI-dC) as a nonspecific competitor were used to demonstrate the specificity of protein binding. Samples were subjected to electrophoresis at $120 \mathrm{~V}$ in $1 \%$ agarose gel with $0.5 \mathrm{X}$ Tris-borate-EDTA for $1.5 \mathrm{~h}$; the gel was then electrophoretically transferred to a nylon membrane at $380 \mathrm{~mA}$ for $60 \mathrm{~min}$, and cross-linked DNA was transferred to the membrane using a UV-light cross-linker (UVP, LLC, Upland, CA, USA). After the membrane was cross-linked, biotin-labeled DNA was detected by chemiluminescence, which was developed using a chemiluminescence imaging 
Table II. Primers for VCAM-1, PPAR $\gamma$ and $\beta$-actin.

\begin{tabular}{lll}
\hline Gene $(\mathrm{bp})$ & \multicolumn{1}{c}{ Upstream primer } & \multicolumn{1}{c}{ Downstream primer } \\
\hline VCAM-1 (387) & 5'-TCGCGGTCTTGGGAGCCTCA-3' & 5'-CCGTGACCGGCTTCCCAACC-3' \\
PPAR $\gamma(91)$ & 5'-GGGCAAGAGAATCCACGAAG-3' & 5'-GTTGTTGCTGGTCTTTCCCG-3' \\
$\beta$-actin (93) & 5'-CAGAAGGAGATTACTGCTCTGGCT-3' & 5'-GGAGCCACCGATCCACACA-3' \\
\hline
\end{tabular}

VCAM-1, vascular cell adhesion molecule 1; PPAR $\gamma$, peroxisome proliferator-activated receptor- $\gamma$.

system (Bio-Rad, Shanghai, China). The membrane was exposed to X-ray film for 5-10 min. PPAR $\gamma$ and NF- $\mathrm{kB}$ activities were determined from the integrated density value of the band.

Reverse transcription-quantitative polymerase chain reaction $(R T-q P C R)$. Liver samples were stored at $-80^{\circ} \mathrm{C}$ until total RNA extraction using TRIzol reagent (Invitrogen Life Technologies, Carlsbad, CA, USA). The expression levels of VCAM-1 and PPAR $\gamma$ in the ischemic liver were quantified using RT-qPCR. The sequences for the VCAM-1, PPAR $\gamma$ and $\beta$-actin specific primers are displayed in Table II. In brief, amplification and detection were performed using the ReverTra Ace qPCR RT kit (FSQ-101; Toyobo, Osaka, Japan), according to the manufacturer's instructions, and FastStart Universal SYBR Green Master (Roche, Basel, Switzerland). The analysis was conducted using a LightCycler qPCR apparatus (Bio-Rad, Hercules, CA, USA) with the following reaction profile: $10 \mathrm{~min}$ at $95^{\circ} \mathrm{C}, 40$ cycles at $95^{\circ} \mathrm{C}$ for $25 \mathrm{sec}, 55^{\circ} \mathrm{C}$ for $25 \mathrm{sec}$, $72^{\circ} \mathrm{C}$ for $50 \mathrm{sec}$ and $72^{\circ} \mathrm{C}$ for $5 \mathrm{~min}$. All primers and probes were purchased from SBS Genetech Co. Ltd. (Beijing, China). The expression of each mRNA was normalized against $\beta$-actin prior to the calculation of the fold change. The fold increase in the expression of each mRNA in the ischemic liver lobe was calculated.

Gelatin zymography for MMP-2/9 activity. Zymography was used to assay MMP enzyme expression as described by Herron et al (21) in tissue extracts following the manufacturer's instructions. Gelatinolytic bands were scanned and digitized for quantification of band intensity using Gel-Pro Analyzer software, version 3.1 (Cold Spring Harbor Laboratory).

Statistical analysis. Data are expressed as mean \pm standard error of the mean. Data were analyzed by one-way analysis of variance with a subsequent Student-Newman-Keuls test. The Kaplan-Meier method with log rank test was used for survival analysis. $\mathrm{P}<0.05$ was considered to indicate a statistically significant difference. Statistical analysis was performed using SPSS software, version 13.0 (SPSS Inc., Chicago, IL, USA).

\section{Results}

Rosiglitazone significantly inhibits tumor metastasis following hepatic $I / R$. The sham and control groups were compared to determine whether hepatic I/R affects liver metastasis following the portal injection of $\mathrm{H} 22$ cells. A total of 2/10 control group mice survived for 12 days post-surgery, and the majority of mice in the control group (9/10) developed hepatic metastases. In the sham group, 5/10 mice survived 12 days (Fig. 1A). Histopathological examination revealed a clear margin between the tumor and normal liver tissue. Furthermore, necrotic areas were observed in all liver sections, covering $5-10 \%$ of the liver tissue in the sham group and $15-25 \%$ in the control group with accumulated PMNs. Tumor metastasis was located predominantly in proximity of the necrotic areas (Fig. 1B). The largest tumor metastases were observed in the Ro + GW group (Fig. 1C). Furthermore, 2 mice developed renal metastases (Fig. 1D) and 1 mouse developed lung metastases in the Ro + GW group. As presented in Fig. 1E, in the sham group, the left lobe of the liver exhibited fewer micrometastases compared with the left lobe of the control group, which was ischemic, as evaluated by the percentage of HRA ( $\mathrm{P}=0.0032)$. No statistically significant difference was observed in tumor load between the right lobe of the sham mice and the right lobe (non-ischemic lobes) of mice subjected to I/R ( $\mathrm{P}=0.089)$. Therefore, hepatic $\mathrm{I} / \mathrm{R}$ increased the development of hepatic metastasis in portal-injected tumor cells in mice. In the Ro group, 4/10 mice survived at the selective time-point, but none survived in the Ro + GW group ( $\mathrm{P}=0.041$, Ro vs. control group; $\mathrm{P}<0.001$, Ro $+\mathrm{GW}$ vs. control group). A marked increase in tumor load was observed in the control and Ro + GW groups. Significant differences were observed in tumor load in the left ischemic lobes of the control and Ro groups $(\mathrm{P}=0.01009)$. Mice in the Ro + GW group exhibited a detectable but insignificant acceleration of tumor metastases compared with the control group $(\mathrm{P}=0.064)$.

Protective effect of PPAR $\gamma$ activation on liver function. The degree of damage to liver function was determined by measuring ALT expression levels. Mice that were subjected to $70 \%$ hepatic ischemia followed by $8 \mathrm{~h}$ of reperfusion exhibited a significant increase in ALT expression levels compared with those in the sham group; the increase observed at $8 \mathrm{~h}$ was particularly marked $(3,649.1 \pm 440.1$ vs. $45.5 \pm 18.3 \mathrm{U} / 1$, respectively). Rosiglitazone appeared to exert an insignificant effect on I/R liver injury at $2 \mathrm{~h}$ reperfusion compared with that in the control group (ALT, $1,017.3 \pm 365.9$ vs. $1,134.2 \pm 320.5 \mathrm{U} / 1$, respectively; $\mathrm{P}=0.191)$. However, PPAR $\gamma$ activation caused a significant reduction in ALT expression levels after $8 \mathrm{~h}$ reperfusion in the Ro group compared with the control group (ALT, 1,691.9 \pm 398.6 vs. 3,649.1 $\pm 440.1 \mathrm{U} / 1$, respectively; $\mathrm{P}<0.0001$ ). In the mice of the Ro + GW group, the protective action of rosiglitazone on ALT expression levels was significantly diminished by GW9662 at the 8 and 
A
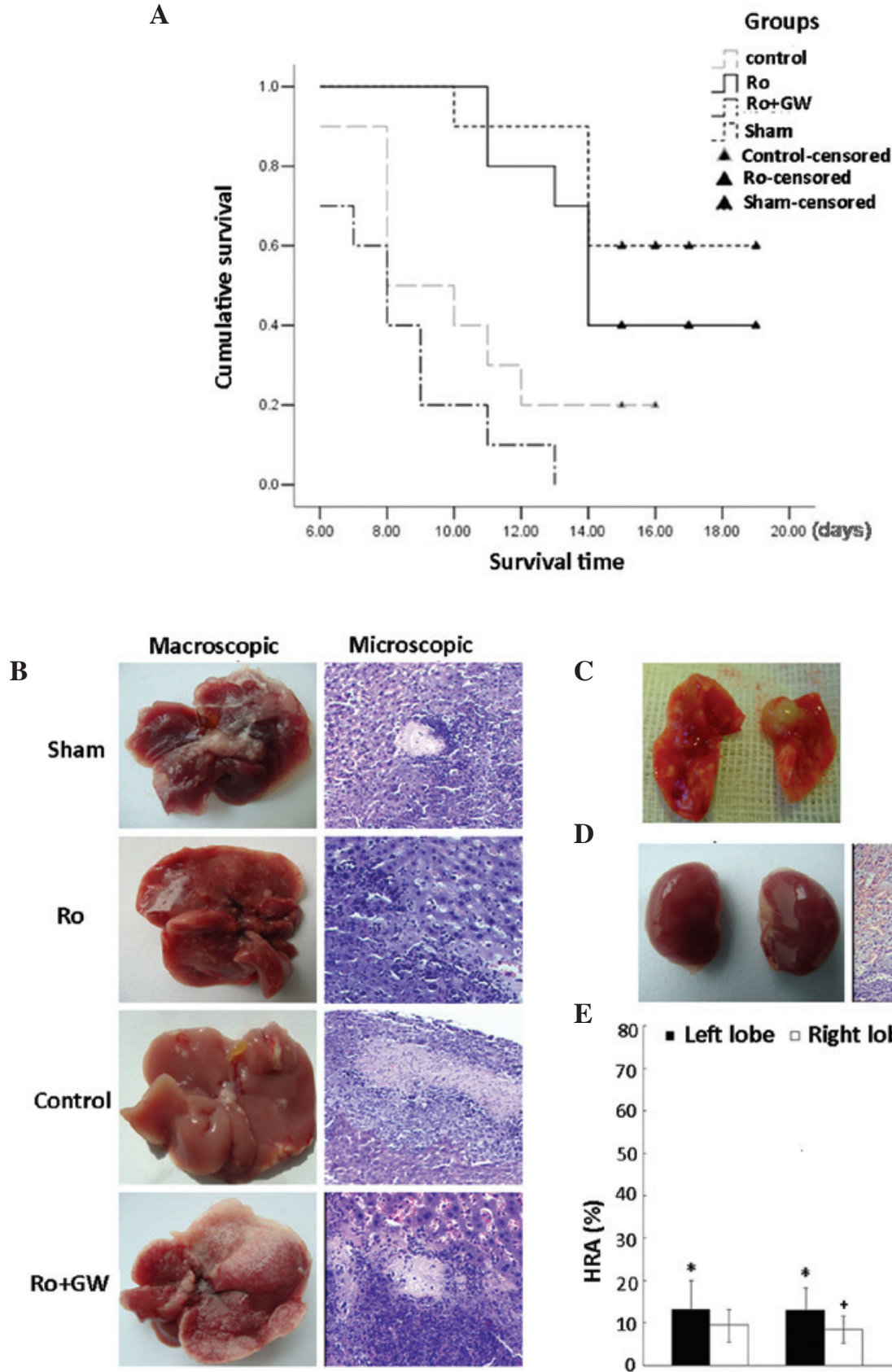

C

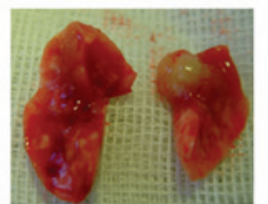

D

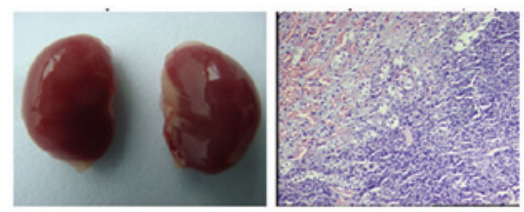

$\mathbf{E}$

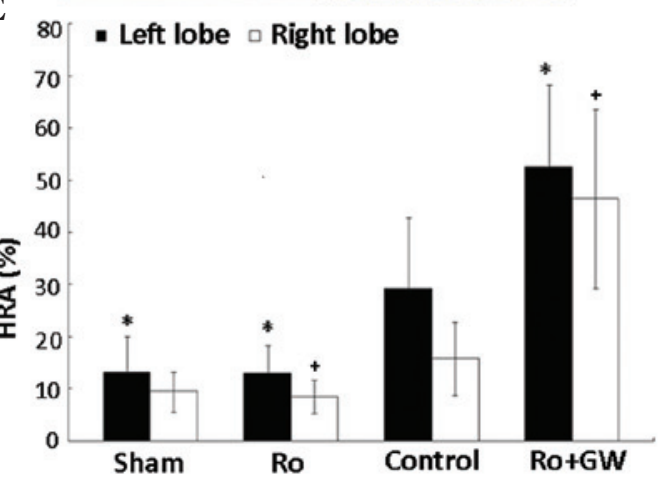

Figure 1. Effect of ischemia/reperfusion (I/R) on hepatic metastasis in a mouse model. (A) Median survival times were as follows: Sham group, 16.6 days; control group, 10.3 days; Ro group, 15.3 days; and Ro + GW group, 8.3 days. $\mathrm{P}=0.011$, sham vs. control group; $\mathrm{P}=0.041$, Ro vs. control group; and $\mathrm{P}=0.138$, Ro + GW vs. control group. Tumor metastases were examined macroscopically and using hematoxylin and eosin-stained tissue sections (magnification, x200). (B) Macroscopic and microscopic evaluation in the sham, Ro, control and Ro + GW groups 12 days after the procedure. Under macroscopic examination, metastases were identified in all groups. (C) The greatest amount of lung metastasis was observed in the Ro + GW group. (D) In addition, kidney metastases were primarily observed in the Ro + GW group. (E) Liver tumor load presented as hepatic replacement area (HRA). "P<0.05 vs. control group left lobe; ${ }^{+} \mathrm{P}<0.05$, vs. control group right lobe. Ro, rosiglitazone; Ro + GW, rosiglitazone and GW9662.

$24 \mathrm{~h}$ time points $(\mathrm{P}<0.001, \mathrm{Ro}+\mathrm{GW}$ group vs. the Ro group; Fig. 2).

PPAR $\gamma$ agonist inhibits local immune activation. To clarify the potential molecular mechanisms underlying the protective effect of the PPAR $\gamma$ agonist on liver I/R-associated metastasis, the local expression levels of VCAM-1 and MPO were evaluated in the liver at 2, 8 and $24 \mathrm{~h}$ after reperfusion (Fig. 3A-C and $\mathrm{E}$ ). The data indicate that after $8 \mathrm{~h}$ of reperfusion, there was a $\geq 4$-fold increase in hepatic VCAM-1 mRNA levels in the control group compared with the sham group $(\mathrm{P}<0.001)$. Furthermore, PPAR $\gamma$ agonist treatment significantly downregulated local VCAM-1 mRNA expression levels compared with those in the control group ( $\mathrm{P}=0.002$ at $2 \mathrm{~h} ; \mathrm{P}=0.0037$ at $8 \mathrm{~h} ; \mathrm{P}=0.035$ at $24 \mathrm{~h}$ ). Immunohistochemistry was used to determine the expression of VCAM-1 at the protein level and the results were similar to those for VCAM-1 mRNA (Fig. 3B and E). To determine whether rosiglitazone pretreatment was accompanied by reduced PMN sequestration, the MPO levels in the liver were determined. Mice that were treated 


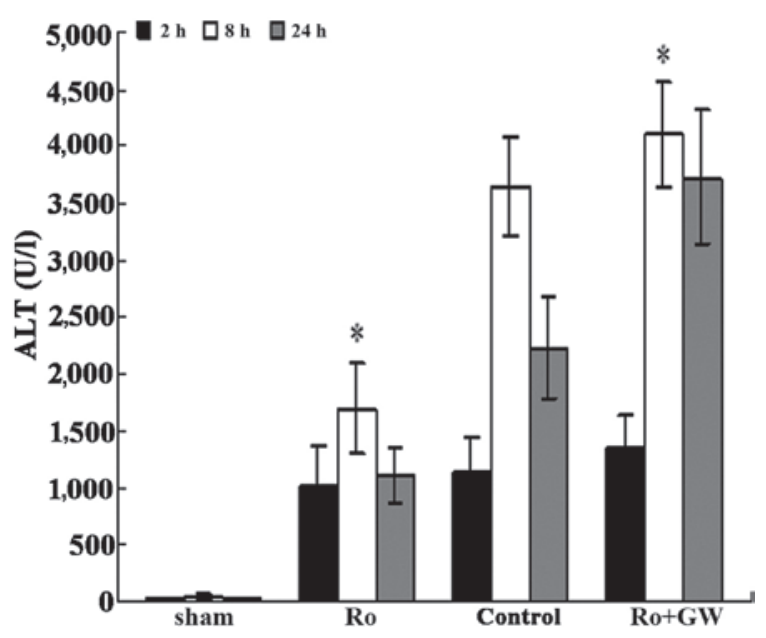

Figure 2. Effect of rosiglitazone (Ro) and GW9662 (GW) on liver I/R injury. Mice were pretreated with $1 \mathrm{mg} / \mathrm{kg}$ rosiglitazone (Ro) alone or together with $1 \mathrm{mg} / \mathrm{kg}$ GW9662 (GW) dissolved in dimethyl sulfoxide $1 \mathrm{~h}$ prior to induction of ischemia. The ALT levels in the hepatic homogenate from mice treated with vehicle, Ro or GW9662 + Ro were measured at 2, 8 and $24 \mathrm{~h}$ after reperfusion to determine the degree of damage to liver function. $\mathrm{P}<0.05$ vs. the control (I/R) group. Mice in the control group exhibited a significant increase in ALT levels compared with the sham group, which were particularly high after $8 \mathrm{~h}$ of reperfusion $(\mathrm{P}<0.001)$. No statistically significant difference was observed between the control and Ro groups after $2 \mathrm{~h}$ of reperfusion. A significant reduction in ALT levels was observed in the Ro group compared with the control and Ro + GW groups after $8 \mathrm{~h}$ of reperfusion $(\mathrm{P}<0.0001)$. ALT, alanine aminotransferase; $\mathrm{I} / \mathrm{R}$, ischemia/reperfusion.

with rosiglitazone prior to I/R injury exhibited reduced MPO levels, indicating reduced neutrophil accumulation, compared with those in the control group $(\mathrm{P}=0.104$ at $2 \mathrm{~h} ; \mathrm{P}=0.056$ at $8 \mathrm{~h}$; $\mathrm{P}=0.037$ at $24 \mathrm{~h}$ ). The effects of rosiglitazone on MPO levels were inhibited in the Ro + GW group mice at all time points (Fig. 3C), as were the effects on PPAR $\gamma$ (Fig. 3D).

I/R-induced expression of MMP-9 is inhibited by rosiglitazone in the liver of the mice. Whether activation by aPAR $\gamma$ agonist inhibited matrix degradation at the protein level was investigated. Samples were assessed via gelatin zymography. As hypothesized, MMP activity was detected in the hepatic homogenates after $2 \mathrm{~h}$ reperfusion, and MMP was highly expressed at 8 and $24 \mathrm{~h}$ after reperfusion. I/R significantly increased the activity of MMP in the liver as the reperfusion time increased. An intravenous injection of rosiglitazone notably reduced MMP activity. Almost undetectable bands were observed in the liver homogenates of the rosiglitazone-treated mice after $2 \mathrm{~h}$ perfusion compared with the other groups. By contrast, a prominent band was observed in the control and Ro $+\mathrm{GW}$ groups compared with the Ro group at the same time-point (Fig. 4). Furthermore, the molecular markers indicated that the band observed corresponded to MMP-9. Conversely, MMP-2 activity was almost undetectable in all groups at 2, 8 and $24 \mathrm{~h}$ after reperfusion (data not shown). Thus, the results indicate that MMP-9 is the major MMP involved in gelatinolysis.

Effects of rosiglitazone on NF- $\kappa B$ signaling. To identify the intracellular signaling pathways potentially involved in the protective effect exerted by rosiglitazone pretreatment, EMSA analysis was used to measure PPAR $\gamma$ and NF-kB p65 activation. Liver I/R activated NF- $\kappa B$ p65 in a time-dependent manner.
NF- $\mathrm{KB}$ p 65 was maximally activated after $8 \mathrm{~h}$ reperfusion and the activation persisted until $24 \mathrm{~h}$ reperfusion. Rosiglitazone inhibited the I/R-induced activation of NF- $\mathrm{kB}$ p 65 after 8 and $24 \mathrm{~h}$ reperfusion. The preservation of NF- $\mathrm{KB}$ p 65 activity afforded by rosiglitazone was attenuated by GW9662 pretreatment at all reperfusion time points (Fig. 5).

\section{Discussion}

Tumor metastasis is influenced by a wide range of factors, including cellular adhesion molecules, extracellular matrix proteins, proteases and chemokines (7). In the current study, short-term treatment of mice with rosiglitazone, a potent PPAR $\gamma$ agonist, conferred protection against hepatic $\mathrm{I} / \mathrm{R}$-induced tumor metastasis via a number of mechanisms.

It is widely accepted that tumor metastases occur more frequently following surgical stress (4-6,16); however, the molecular and cellular mechanisms underlying this phenomenon remain largely unknown. Previous studies have demonstrated that hepatic I/R-induced injury during surgery may activate a number of proinflammatory cytokines, including E-selectin (5), vascular endothelial growth factor (22) and MMPs (16), which promote tumor invasion and metastasis. Adhesion of tumor cells onto the vascular endothelium is a prerequisite for tumor cell extravasation. Inhibition of the cytokines involved in this mechanism may represent a potential approach to limiting metastasis following hepatic I/R. Therefore, promoting tumor metastasis through hepatic $\mathrm{I} / \mathrm{R}$ may be a multifactorial process. Reducing the cytokines involved may serve additional key functions in the reduction of tumor metastasis following $\mathrm{I} / \mathrm{R}$.

First, hepatic I/R was confirmed to promote the metastases of liver tumor cells. Intraportal injection of $\mathrm{H} 22$ tumor cells following $\mathrm{I} / \mathrm{R}$ resulted in the formation of a number of metastatic foci on the surface of the liver. The tumor load (scored using HRA) in the left lobes of the control group was significantly increased compared with that of the sham group at 12 days after surgery. Furthermore, it was observed that metastases were preferentially located in the margin of the visceral surface of the ischemic lobes. Potential explanations for this observation include: i) The margin of the visceral surface of the ischemic lobe is more susceptible to $\mathrm{I} / \mathrm{R}$ injury compared with other sites of the liver; ii) metastases of $\mathrm{H} 22$ tumor cells are more easily captured within the microvasculature of the margin of the liver in mice.

In addition, no statistical difference in tumor load was observed between the right lobe in the sham-operated mice and the right (non-ischemic) lobes of the mice subjected to $\mathrm{I} / \mathrm{R}(\mathrm{P}=0.089)$. This result contrasts with a study by Tamagawa et al (22), which indicated that cytokines produced locally in response to hepatic ischemia may be released into the circulatory system, reach the non-ischemic lobe and bind to receptors on the cancer cells to promote metastases. However, the authors induced partial hepatic ischemia 3 days after the tumor cell inoculation, which is inconsistent with the protocol of the present study. The present study design may better gauge the effect of I/R on tumor TEM. The present results indicate that hepatic $I / R$ exerts a local inflammatory effect on the invasion of tumor cells into circulation and does not involve systemic cytokines in the blood. 
A

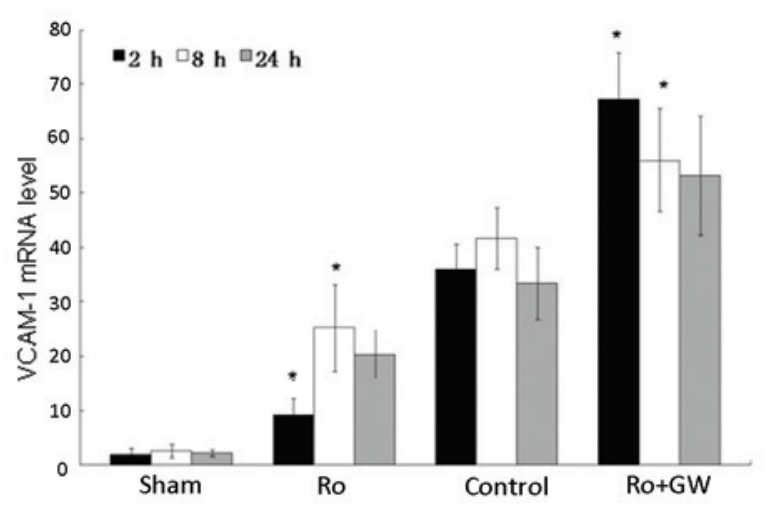

C

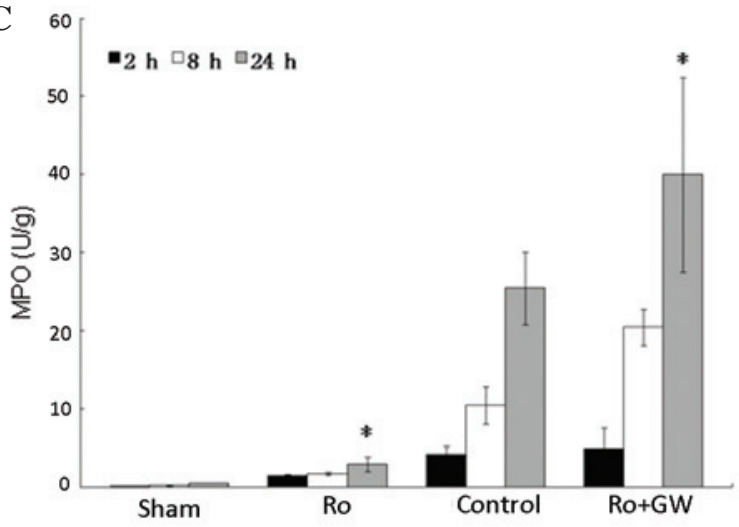

$\mathbf{E}$

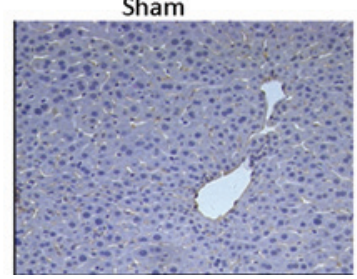

Ro

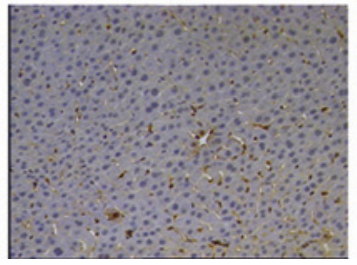

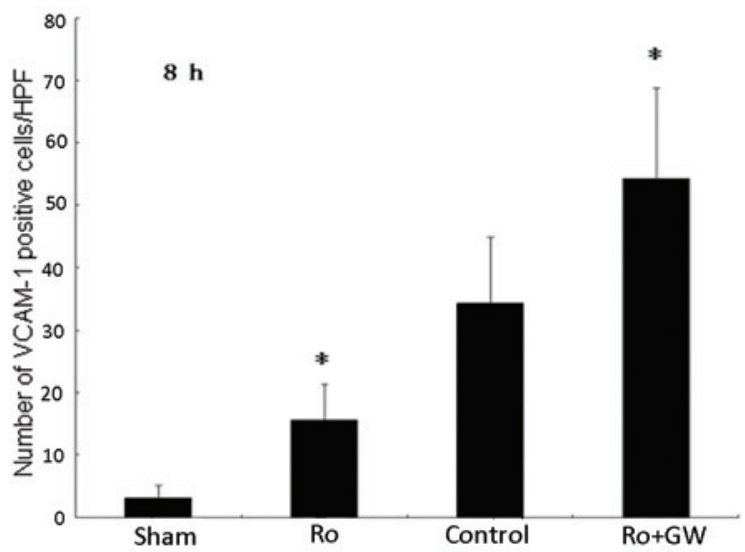

D
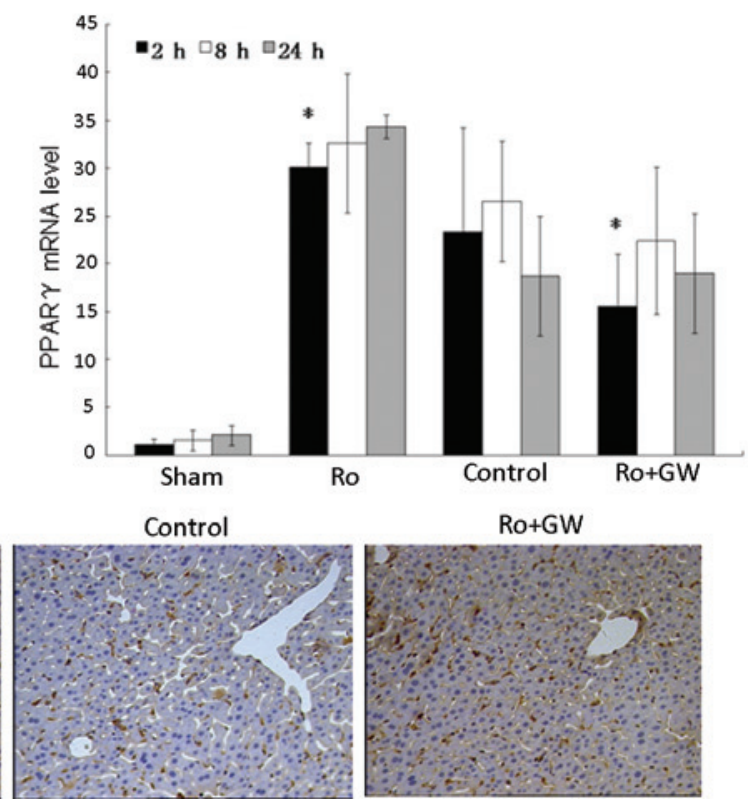

Figure 3. Expression of VCAM-1, MPO and PPAR $\gamma$ following I/R of the liver in the four groups. (A, B and E) VCAM-1, (C) MPO and (D) PPAR $\gamma$ levels were detected in the liver homogenates of the four groups. VCAM-1 and MPO were detected after $2 \mathrm{~h}$ of reperfusion, and the proteins and mRNA were highly expressed after 8 and $24 \mathrm{~h}$ of reperfusion. (A) After $8 \mathrm{~h}$ of reperfusion, there was a $\geq 4$-fold increase in hepatic VCAM- 1 mRNA levels in the control group compared with the sham group $(\mathrm{P}<0.001)$ and PPAR $\gamma$ agonist treatment significantly downregulated local VCAM-1 expression compared with that in the control group ( $\mathrm{P}=0.002$ at $2 \mathrm{~h} ; \mathrm{P}=0.0037$ at $8 \mathrm{~h} ; \mathrm{P}=0.035$ at $24 \mathrm{~h}$ ). (B and $\mathrm{E}$ ) The expression of VCAM-1 in the liver at $8 \mathrm{~h}$ after reperfusion showed similar results to the VCAM-1 mRNA levels. Positive cells are stained brown (magnification, x100). To determine whether rosiglitazone pretreatment was accompanied by decreased PMN sequestration, liver MPO levels were measured and showed that mice that were treated with rosiglitazone prior to I/R injury had reduced neutrophil accumulation compared with the control group ( $\mathrm{P}=0.104$ at $2 \mathrm{~h} ; \mathrm{P}=0.056$ at $8 \mathrm{~h} ; \mathrm{P}=0.037$ at $24 \mathrm{~h})$, and the effects were abolished by GW9662 at all time-points. (D) PPAR $\gamma$ levels in the four groups. VCAM-1, vascular cell adhesion molecule 1; Ro, rosiglitazone; HPF; high power field; GW, GW9662; MPO, myeloperoxidase; PPAR $\gamma$, peroxisome proliferator-activated receptor- $\gamma ; \mathrm{I} / \mathrm{R}$, ischemia/reperfusion. ${ }^{\text {"P }}<0.05$ vs. control group at the same time-point.

Previous studies have indicated that PPAR $\gamma$ activation confers hepatoprotective effects against hepatic I/R $(17,23)$. The results of the present study verified that the PPAR $\gamma$-selective agonist rosiglitazone significantly reduced hepatic injury suffered following I/R, potentially via ALT and neutrophil sequestration, compared with that in the control and Ro $+\mathrm{GW}$ groups. Furthermore, PPAR $\gamma$ activation was more evident in the Ro group than in the other groups. Next, the effects of PPAR $\gamma$ on hepatic I/R-associated metastasis were investigated. PPAR $\gamma$ treatment significantly inhibited the increase in tumor load in the mice subjected to hepatic I/R compared with that in the control group $(\mathrm{P}<0.05)$. By contrast, GW9662 treatment increased the tumor load induced by $\mathrm{I} / \mathrm{R}$. Then, to investigate the pathophysiological role of PPAR $\gamma$ in I/R-associated metastasis, the expression of a number of inflammatory molecules associated with liver metastases in mice were detected after 2,8 and $24 \mathrm{~h}$ reperfusion. These results were analyzed in an attempt to determine the correlation between inflammatory mediators and post-operative metastases. The results indicate that VCAM-1 protein expression, similar to MPO and MMP-9 expression, was virtually undetectable in the sham group, but significantly increased and peaked after $8 \mathrm{~h}$ of reperfusion in the other 3 groups at all time points. The levels were particularly elevated during the initial $24 \mathrm{~h}$ after I/R, which is a crucial period for liver cancer metastases. Therefore, elevated proinflammatory cytokines may be involved in early intrahepatic metastases. 
A

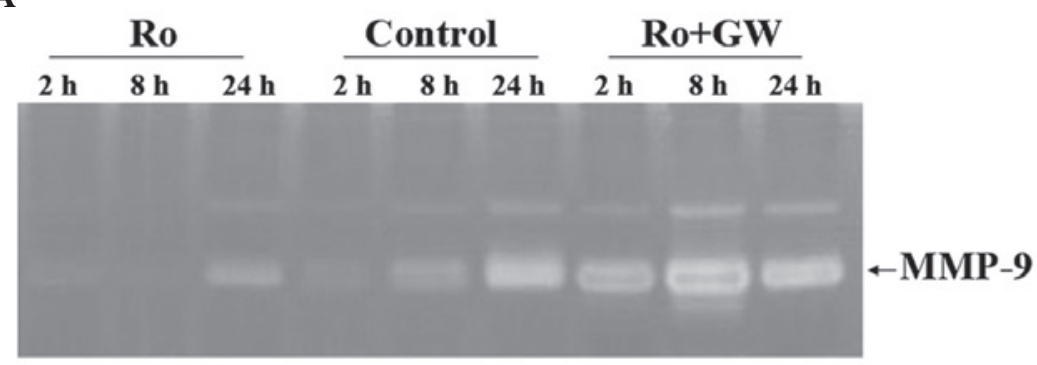

B

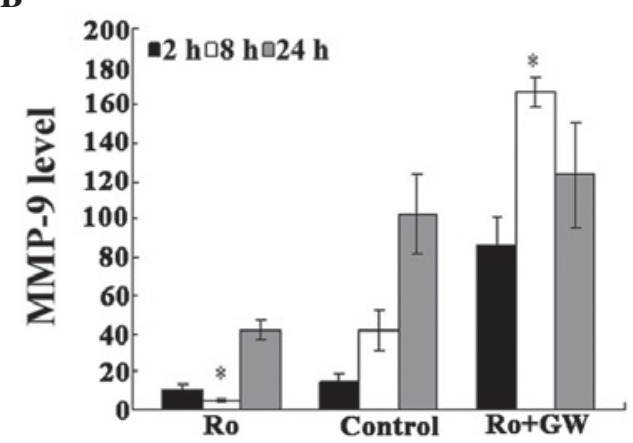

Figure 4. MMP-9 expression and activity in the liver homogenates. (A) MMP-9 expression was analyzed using reverse transcription-quantitative polymerase chain reaction. (B) MMP-9 activity was detected using gelatin zymography after $2 \mathrm{~h}$ of reperfusion, and was high after $8 \mathrm{~h}$ and $24 \mathrm{~h}$ of reperfusion. Ischemia/reperfusion significantly increased the MMP-9 activity of the liver with prolonged reperfusion time. Almost undetectable bands were identified in the liver homogenates of the Ro group mice after $2 \mathrm{~h}$ of perfusion compared with the other groups. A prominent band was also observed in the control and Ro + GW groups compared with the Ro group ( $\mathrm{P}=0.00178$, control vs. Ro group; $\mathrm{P}<0.0001$ control vs. Ro $+\mathrm{GW}$ group). ${ }^{*} \mathrm{P}<0.05$ vs. control. Ro, rosiglitazone; GW, GW9662; MMP-9, matrix metalloproteinase-9.

A

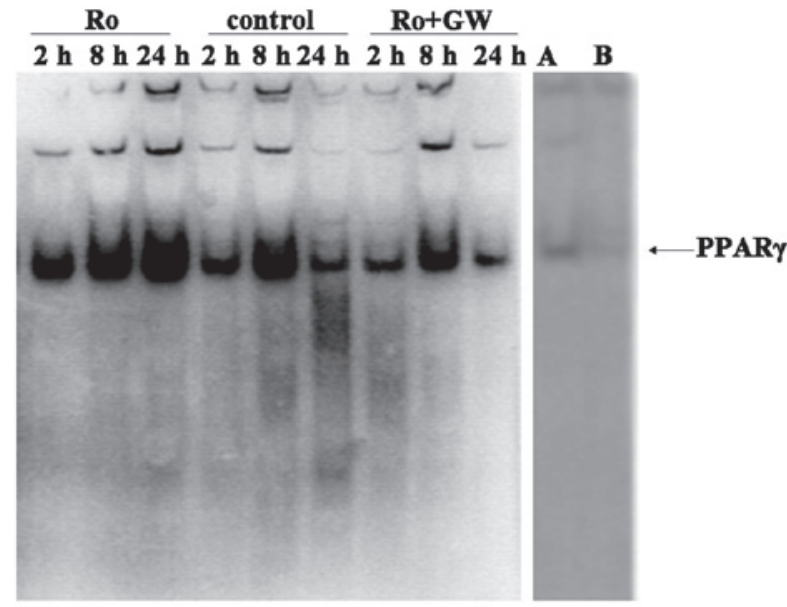

B

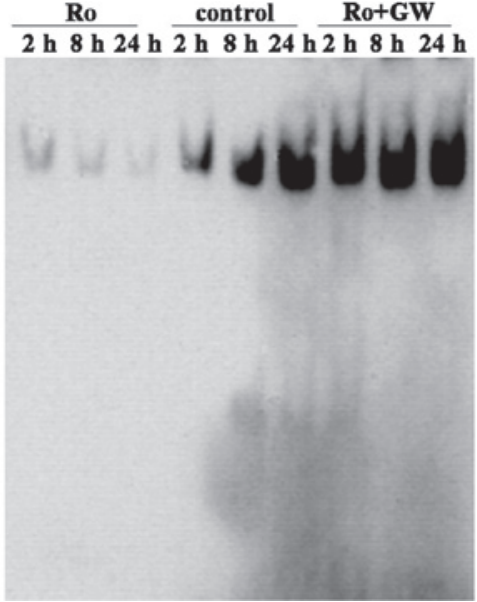

$\mathbf{A}$

B

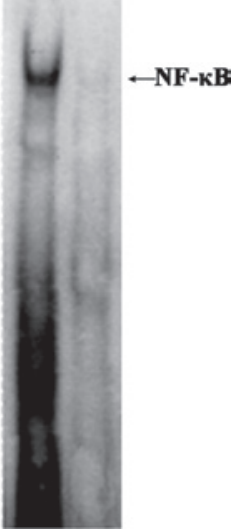

Figure 5. Effect of rosiglitazone and GW9662 pretreatment on PPAR $\gamma$ and NF- $\mathrm{kB}$. Liver nuclear extracts from mice that underwent liver ischemia and 2,8 and $24 \mathrm{~h}$ reperfusion were analyzed using an electrophoretic mobility shift assay (EMSA). (A) PPAR $\gamma$ activation was detected. (B) Liver I/R activated NF- $\kappa \mathrm{B}$ in the control group in a time-dependent manner. The I/R-induced activation of NF- $\kappa B$ was inhibited by Ro; GW attenuated the inhibitory effect. Data are repre-

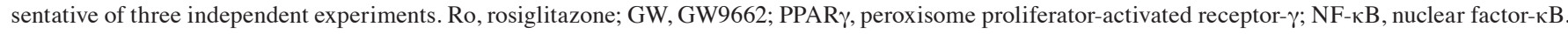

The present results are consistent with those of previous studies, which indicate that hepatic I/R induces the expression of E-selectin and promotes liver metastases of colon cancer in rats $(5,24,25)$. The following phenomena may explain how tumor recurrence is enhanced by I/R-induced inflammatory cytokines. First, inflammatory cytokines may promote cell adhesion. Tumor cells with higher metastatic potentials exhibit a significantly higher adhesion capability for microvascular endothelial cells $24 \mathrm{~h}$ after hepatic I/R compared with that in the absence of I/R (26,27). Second, inflammatory cytokines promote angiogenesis $(28,29)$. Third, pro-inflammatory cytokines indirectly stimulate cell proliferation $(30,31)$ and inhibit cell apoptosis (32).

Extracellular matrix and basement membranes function as physical barriers to tumor cell metastasis from their primary site to target organs (33). The ability of cancer cells to metastasize depends on their ability to degrade type-IV collagen. MMPs are the primary proteolytic enzymes involved in the invasion of tumor cells $(33,34)$. In the present model of $\mathrm{H} 22$ cell metastatic tumors, significant gelatinase activity was detected in the metastatic tumor-bearing mouse liver. Furthermore, MMP-9 expression was evident in the homogenates of the tumor-bearing liver tissue. Gelatin zymographic analysis of the liver homogenates clearly demonstrated that MMP-9 is a major contributor to the gelatinolysis in the tumor-bearing mouse liver following the intraportal inoculation of H22 tumor cells. MMP-9 activity was markedly suppressed following the intravenous injection of rosiglitazone at all time points.

Although PMNs may be cytotoxic to tumor cells, they have been demonstrated to promote tumor adhesion, transendothelial migration and facilitate the activation of angiogenesis under certain circumstances $(35,36)$. MPO is an enzyme restricted primarily to PMNs and may reflect the number of PMNs in the tissue. Rosiglitazone reduced MPO activity in the liver compared with that in the control and Ro + GW groups. This indicates that the PPAR $\gamma$ agonist reduces PMN infiltration into the liver parenchyma. These data suggest that the protective ability of rosiglitazone against hepatic I/R-associated metastases was partially a result of the 
reduction in neutrophil sequestration. There are two possible mechanisms by which PMN may assist tumor cell migration across the endothelial barrier. The first possibility is that $I / R$ produces reactive oxygen species from PMNs via the action of cytokines $(33,37)$, which are able to damage endothelial cells and produce circulatory disturbances. Tumor cells present in the bloodstream under these conditions may be rapidly invaded. The other possibility is that an interaction may occur between PMNs and tumor cells wherein PMNs, via an adhesion receptor-dependent mechanism, may bind to tumor cells and facilitate their migration through the vascular endothelium (36). However, it was not possible to determine which cells in the liver contributed to the cytokine activity discussed in the present experimental model. Certain tumor cells, endothelial cells, macrophages and hepatocytes produce large amounts of adhesion molecules, chemotactic molecules, inducible nitric oxide synthase and MMPs $(38,39)$. Additional data are required to identify the source of these inflammatory factors in vivo. Collectively, the beneficial effect of PPAR $\gamma$ agonists on hepatic I/R-associated metastases may be, at least in part, dependent on the restraints of the local inflammatory response in the liver.

Aberrantly produced PPAR $\gamma$ may bind to its receptors and result in the altered activation of particular signaling pathways, including the NF- $\kappa \mathrm{B}$ pathway (17-19). The NF- $\kappa \mathrm{B}$ signaling pathway has been demonstrated to be actively involved in $\mathrm{HCC}$ development by controlling angiogenesis (38), cell motility and cell proliferation $(40,41)$. Furthermore, the $N F-\kappa B$ pathway is a key factor in inflammation $(39,42)$. NF- $\kappa \mathrm{B}$ regulates the expression of VCAM-1, MPO and MMP-9, which are associated with tumor metastases and inflammation $(38,39,42)$. Thus, it may be hypothesized that the activation of NF- $\kappa$ B by rosiglitazone, a marker of inflammatory responses frequently detected in tumors, constitutes a mechanistic link between I/R and cancer. Thus, NF- $\kappa \mathrm{B}$ activation in hepatic I/R is essential for promoting tumor metastases.

A number of studies have indicated that PPAR $\gamma$ ligands are potential chemopreventive agents for liver carcinogenesis $(32,40)$. The mechanisms underlying their actions appear to involve the inhibition of cell proliferation and the induction of apoptosis. However, this anticarcinogenic effects requires an extended treatment period and a flushing dose (>40 mg/kg). In the present study, rosiglitazone $(1 \mathrm{mg} / \mathrm{kg})$ was administered $1 \mathrm{~h}$ prior to hepatic I/R and the intravenous injection of the $\mathrm{H} 22$ cells. On the basis of these results, the inhibition of tumor metastasis in the rosiglitazone-treated mice was highly unlikely to be due to the direct cytotoxic effects of injected tumor cells. Further studies are required to eliminate the possibility of the direct cytotoxic effects of rosiglitazone on H22 cells.

The short-term administration of rosiglitazone can limit I/R-induced hepatic injury. Thus, this drug may be used in certain I/R processes, particularly in emergency procedures such as liver surgery and transplantation, as there is limited time in which to pretreat patients with PPAR $\gamma$ agonists.

In summary, hepatic I/R results in microcirculatory disturbances and excessive inflammation, which induce PMNs, VCAM-1 and MMP-9, all of which may serve key functions in the accelerated metastases of HCCs following I/R. PPAR $\gamma$ activation appears to offer a promising strategy in metastases therapy by reducing the strong stimulus of $I / R$, which promotes hematogenous micrometastases in the liver. Therefore, the PPAR $\gamma$ agonist rosiglitazone may be an efficient agent for preventing hepatic I/R-associated metastases.

\section{Acknowledgements}

The present study was funded by a grant from the China Postdoctoral Science Foundation (no. 2009045513).

\section{References}

1. Fu SY, Lau WY, Li AJ, Yang Y, Pan ZY, Sun YM, Lai EC, Zhou WP and Wu MC: Liver resection under total vascular exclusion with or without preceding Pringle manoeuvre. $\mathrm{Br}$ J Surg 97: 50-55, 2010.

2. Makuuchi M, Takayama T, Kubota K, Kimura W, Midorikawa Y, Miyagawa S and Kawasaki S: Hepatic resection for hepatocellular carcinoma - Japanese experience. Hepatogastroenterology 45 (Suppl 3): 1267-1274, 1998.

3. Llovet JM and Bruix J: Systematic review of randomized trials for unresectable hepatocellular carcinoma: Chemoembolization improves survival. Hepatology 37: 429-442, 2003.

4. Tsuchiya Y, Sawada S, Yoshioka I, Ohashi Y, Matsuo M, Harimaya Y, Tsukada K and Saiki I: Increased surgical stress promotes tumor metastasis. Surgery 133: 547-555, 2003.

5. Uotani H, Yamashita I, Nagata T, Kishimoto H, Kashii Y and Tsukada K: Induction of E-selectin after partial hepatectomy promotes metastases to liver in mice. J Surg Res 96: 197-203, 2001.

6. Kooby DA, Stockman J, Ben-Porat L, Gonen M, Jarnagin WR, Dematteo RP, Tuorto S, Wuest D, Blumgart LH and Fong Y: Influence of transfusions on perioperative and long-term outcome in patients following hepatic resection for colorectal metastases. Ann Surg 237: 860-869, discussion 869-870, 2003.

7. Jarrar D, Chaudry IH and Wang P: Organ dysfunction following hemorrhage and sepsis: Mechanisms and therapeutic approaches (Review). Int J Mol Med 4: 575-583, 1999.

8. Selzner M and Clavien PA: Failure of regeneration of the steatotic rat liver: Disruption at two different levels in the regeneration pathway. Hepatology 31: 35-42, 2000.

9. Jaeschke H, Bautista AP, Spolarics Z and Spitzer JJ: Superoxide generation by Kupffer cells and priming of neutrophils during reperfusion after hepatic ischemia. Free Radic Res Commun 15: 277-284, 1991.

10. Higashiyama A, Watanabe $H$, Okumura $\mathrm{K}$ and Yagita $\mathrm{H}$ : Involvement of tumor necrosis factor alpha and very late activation antigen 4/vascular cell adhesion molecule 1 interaction in surgical-stress-enhanced experimental metastasis. Cancer Immunol Immunother 42: 231-236, 1996.

11. Nicoud IB, Jones CM, Pierce JM, Earl TM, Matrisian LM, Chari RS and Gorden DL: Warm hepatic ischemia-reperfusion promotes growth of colorectal carcinoma micrometastases in mouse liver via matrix metalloproteinase-9 induction. Cancer Res 67: 2720-2728, 2007.

12. Miles FL, Pruitt FL, van Golen KL and Cooper CR: Stepping out of the flow: Capillary extravasation in cancer metastasis. Clin Exp Metastasis 25: 305-324, 2008.

13. Da Costa ML, Redmond HP, Finnegan N, Flynn M and Bouchier-Hayes D: Laparotomy and laparoscopy differentially accelerate experimental flank tumour growth. Br J Surg 85: 1439-1442, 1998.

14. Konstantopoulos K and Thomas SN: Cancer cells in transit: The vascular interactions of tumor cells. Annu Rev Biomed Eng 11: 177-202, 2009.

15. Abdelrahman M, Sivarajah A and Thiemermann C: Beneficial effects of PPAR-gamma ligands in ischemia-reperfusion injury, inflammation and shock. Cardiovasc Res 65: 772-781, 2005.

16. Cuzzocrea S: Peroxisome proliferator-activated receptors gamma ligands and ischemia and reperfusion injury. Vascul Pharmacol 41: 187-195, 2004.

17. Kuboki S, Shin T, Huber N, Eismann T, Galloway E, Schuster R, Blanchard J, Zingarelli B and Lentsch AB: Peroxisome proliferator-activated receptor-gamma protects against hepatic ischemia/reperfusion injury in mice. Hepatology 47: 215-224, 2008. 
18. Kohn EC: Invasion and metastasis: Biology and clinical potential. Pharmacol Ther 52: 235-244, 1991.

19. Tantivejkul K, Kalikin LM and Pienta KJ: Dynamic process of prostate cancer metastasis to bone. J Cell Biochem 91: 706-717, 2004.

20. van der Bilt JD, Kranenburg O, Nijkamp MW, Smakman N, Veenendaal LM, Te Velde EA, Voest EE, van Diest PJ and Borel Rinkes IH: Ischemia/reperfusion accelerates the outgrowth of hepatic micrometastases in a highly standardized murine model. Hepatology 42: 165-175, 2005 .

21. Herron GS, Banda MJ, Clark EJ, Gavrilovic J and Werb Z: Secretion of metalloproteinases by stimulated capillary endothelial cells. II Expression of collagenase and stromelysin activities is regulated by endogenous inhibitors. J Biol Chem 261: 2814-2818, 1986.

22. Tamagawa K, Horiuchi T, Uchinami M, Doi K, Yoshida M, Nakamura T, Sasaki H, Taniguchi M and Tanaka K: Hepatic ischemia-reperfusion increases vascular endothelial growth factor and cancer growth in rats. J Surg Res 148: 158-163, 2008.

23. Akahoril T, Sho M, Hamada K, Suzaki Y, Kuzumoto Y, Nomi T, Nakamura S, Enomoto K, Kanehiro H and Nakajima Y: Importance of peroxisome proliferator-activated receptor $\gamma$ in hepatic ischemia/reperfusion injury in mice. J Hepatol 47: 784-792, 2007.

24. Yu J, Qiao L, Zimmermann L, Ebert MP, Zhang H, Lin W, Röcken C, Malfertheiner P and Farrell GC: Troglitazone inhibits tumor growth in hepatocellular carcinoma in vitro and in vivo. Hepatology 43: 134-143, 2006.

25. Liang $S$ and Dong C: Integrin VLA-4 enhances sialyl-Lewisx/a-negative melanoma adhesion to and extravasation through the endothelium under low flow conditions. Am J Physiol Cell Physiol 295: C701-C707, 2008.

26. Conrad R, Remberger M, Cederlund K, Hentschke P, Sundberg B Ringdén O and Barkholt L: Inflammatory cytokines predominate in cases of tumor regression after hematopoietic stem cell transplantation for solid cancer. Biol Blood Marrow Transplant 12 : 346-354, 2006

27. Hirai T, Matsumoto H, Yamashita K, Urakami A, Iki K, Yamamura $M$ and Tsunoda T: Surgical oncotaxis - excessive surgical stress and postoperative complications contribute to enhancing tumor metastasis, resulting in a poor prognosis for cancer patients. Ann Thorac Cardiovasc Surg 11: 4-6, 2005.

28. McGary EC, Lev DC and Bar-Eli M: Cellular adhesion pathways and metastatic potential of human melanoma. Cancer Biol Ther 1: 459-465, 2002.

29. Mendoza L, Carrascal T, De Luca M, Fuentes AM, Salado C, Blanco J and Vidal-Vanaclocha F: Hydrogen peroxide mediates vascular cell adhesion molecule-1 expression from interleukin-18-activated hepatic sinusoidal endothelium: Implications for circulating cancer cell arrest in the murine liver. Hepatology 34: 298-310, 2001.
30. Mendoza L, Valcárcel M, Carrascal T, Egilegor E, Salado C, Sim BK and Vidal-Vanaclocha F: Inhibition of cytokine-induced microvascular arrest of tumor cells by recombinant endostatin prevents experimental hepatic melanoma metastasis. Cancer Res 64: 304-310, 2004.

31. Grommes C, Landreth GE, Sastre M, Beck M, Feinstein DL, Jacobs AH, Schlegel U and Heneka MT: Inhibition of in vivo glioma growth and invasion by peroxisome proliferator-activated receptor gamma agonist treatment. Mol Pharmacol 70: 1524-1533, 2006.

32. Nishikawa M, Tamada A, Hyoudou K, Umeyama Y, Takahashi Y, Kobayashi Y, Kumai H, Ishida E, Staud F, Yabe Y, et al: Inhibition of experimental hepatic metastasis by targeted delivery of catalase in mice. Clin Exp Metastasis 21: 213-221, 2004.

33. Janani P, Sivakumari K, Geetha A, Yuvaraj S and Parthasarathy C: Bacoside A downregulates matrix metalloproteinases 2 and 9 in DEN-induced hepatocellular carcinoma. Cell Biochem Funct 28: 164-169, 2010.

34. Yoshida M, Horiuchi T, Uchinami M, Tabo T, Kimura N, Yokomachi J, Doi K, Nakamura T, Tamagawa K and Tanaka K: Intermittent hepatic ischemia-reperfusion minimizes liver metastasis in rats. J Surg Res 111: 255-260, 2003.

35. Doi K, Horiuchi T, Uchinami M, Tabo T, Kimura N, Yokomachi J, Yoshida M and Tanaka K: Hepatic ischemia-reperfusion promotes liver metastasis of colon cancer. J Surg Res 105: 243-247, 2002.

36. Nozawa $\mathrm{H}$, Chiu $\mathrm{C}$ and Hanahan D: Infiltrating neutrophils mediate the initial angiogenic switch in a mouse model of multistage carcinogenesis. Proc Natl Acad Sci USA 103: 12493-12498, 2006.

37. Orr FW and Warner DJ: Effects of systemic complement activation and neutrophil-mediated pulmonary injury on the retention and metastasis of circulating cancer cells in mouse lungs. Lab Invest 62: 331-338, 1990

38. Wu QD, Wang JH, Condron C, Bouchier-Hayes D and Redmond HP: Human neutrophils facilitate tumor cell transendothelial migration. Am J Physiol Cell Physiol 280: C814-C822, 2001.

39. Rogers AB and Fox JG: Inflammation and Cancer. I. Rodent models of infectious gastrointestinal and liver cancer. Am J Physiol Gastrointest Liver Physiol 286: G361-G366, 2004.

40. Elsharkawy AM and Mann DA: Nuclear factor-kappaB and the hepatic inflammation-fibrosis-cancer axis. Hepatology 46: 590-597, 2007.

41. Vainer GW, Pikarsky E and Ben-Neriah Y: Contradictory functions of NF-kappaB in liver physiology and cancer. Cancer Lett 267: 182-188, 2008.

42. Baud V and Karin M: Is NF-kappaB a good target for cancer therapy? Hopes and pitfalls. Nat Rev Drug Discov 8: 33-40, 2009. 